\title{
Chapter 17 \\ Open Innovation in SMEs of Developing and Transitional Economies
}

\author{
Hakikur Rahman \\ University of Minho, Portugal \\ Isabel Ramos \\ University of Minho, Portugal
}

\begin{abstract}
Despite being accepted by corporate entrepreneurs and large business houses around the globe, the adaptation of strategies and concepts belonging to the newly evolved dimension of entrepreneurships, and the open innovation (OI), countries in the East, West or Southare yet to accommodate open innovation strategies in their business practices - especially in efforts to reach out to the grassroots communities. By far, firms belonging to the small-and medium-sized enterprises (SMES), irrespective of their numbers and contributions towards their national economies, are far behind in accepting open innovation strategies for their business developments. While talking about this newly emerged business dimension, it comprises of complex and dynamically developed concepts like management of intellectual property aspects, administration of patents and copyright issues, or supervision of market trend for minute details related to knowledge acquisition. All these issues are largely responsible for adding value to the business proposition in terms of economy or knowledge gain, and organizations or entities acting in this aspect deserve comprehensive investigation. As most of the developed countries have already adopted open innovation strategies, finding this as a weak link in terms of entrepreneurships in less developed countries, this chapter intends to seek answers related to the mentioned issues focusing adaption of open innovation strategies in developing and transitional economies. It is a longitudinal study on business houses or national efforts from countries belonging to these categories, deducting from a literature
\end{abstract}

DOI: 10.4018/978-1-4666-1619-6.ch017

Copyright $\odot$ 2012, IGI Global. Copying or distributing in print or electronic forms without written permission of IGI Global is prohibited. 
review. The chapter goes on looking into various aspects of business development incorporating OI concepts, synthesizes building a reasonable framework to be applicable in the target economies, points out to some future research aspects, and concludes the finding of this research. This study is supposed to enhance the knowledge of entrepreneurs and researchers by gaining specific knowledge on the trend of open innovation strategies in developing and transitional economies.

\section{INTRODUCTION}

Innovation is no more an experimentation, but a genuine reality within the entrepreneurships, given the circumstances of economic crisis, global competition and novelties of technologies. Perplexing further to face the reality and overcome crises, enterprises are day by day adopting newly developed ideas, concepts and perceptions to fit into the business dimension from within and outside the boundaries of their entities, thus channeling the entrepreneurships through the paradigm of open innovation (OI). By far, majority of the corporate business houses and multi-national enterprises are competing or collaborating with a common goal in promoting value added products, processes, or services. Notwithstanding, they are transforming the entire entrepreneurship infrastructure to face the reality and move ahead (Van Hemert \& Nijkamp, 2010).

However, a major portion of the business community, despite their justified contribution to economic growth and employment generation, the sector belonging to the small and medium enterprises (SMEs), are not always in advantageous situations in the arena of open innovation due to many factors, seen, unseen, attended, un-attended, researched, deserves further research (United Nations, 2006; World Business Council, 2007).

In this context, Edwards, Delbridge and Munday (2005) argue that, in spite of increasing attention being given to the role of SMEs and innovation there is a gap between what is understood by way of the general innovation literature and the extant literature on innovation in SMEs. They further argue that studies of innovation in SMEs have largely failed to reflect advances in the innovation literature. Supporting these arguments, this study has tried to find out relevance of open innovation among SMEs, and particularly the emergence of OI strategies in developing and transitional economies.

To advance into the context of this research this study has observed that, countries ranking as developed economies are ahead in the race adopting open innovation in their business development, while countries within the developing and transitional economies are struggling to fit into the race of the champions. This chapter based on a study, though not a specific case of one country, has tried to illustrate a few discrete scenarios from five developing countries through horizontal literature review. The chapter has tried to provide a generic context of innovation (inclined to open innovation) in those randomly selected countries, and present challenges they are facing, including some recommendations, before concluding for further extensive research. Along this route, the chapter has tried to build a framework synthesizing the aspects of the findings. It is expected that this study will contribute to enhance knowledge of readers in refreshing the basic concept of open innovation and application of OI strategies among SMEs in developing countries. Furthermore, as majority of OI strategies nowadays are mainly dependent on utilization of information technologies, this study could form a start up literature towards future e-commerce practices adopting strategic and pragmatic business processes. 


\section{BACKGROUND}

Joseph Schumpeter (1883-1950), one of the first theorists who studied the economy through the innovative eye, stated that innovation is about new ways of doing things by combining existing elements into new products through a creative process (De Jong, Vanhaverbeke, Kalvet \& Chesbrough, 2008). Along the way, innovation through the creation, dissemination and utilization of knowledge has become a key driver of economic growth. However, factors influencing innovation performance have changed in this globalized knowledge based economy, partly due to the advent of new information and communication technologies (ICTs), and partly due to the increased global competition. Innovation results from increasingly complex interactions at the local, national, regional and global levels among individuals, firms, industries and other knowledge institutions. Moreover, governments exert a strong influence on the innovation processes through financing and steering of public bodies which are directly responsible for knowledge creation and dissemination (universities, public and private labs, research houses or intermediaries), and through the provision of financial and regulatory inducements (Carayannis, Popescu, Sipp \& Steward, 2006).

In this context, firstly, the new ICTs; secondly, the government and its politics; thirdly, universities and research houses; fourthly, entrepreneurs, suppliers, vendors; and finally, consumers have roles in forming environments pertaining to the launching of innovation within and among entrepreneurships. By far, all these actors need to collaborate and actively participate to create the environment, thus even, turning the innovation processes from traditional or closed ended towards rather non-traditional or open ended, terming it as open innovation.

However, due to the close acquaintance and strong industry-university relationship, including familiarity with new ICTs and exploring their benefits, developed countries are much on the lead in creating and commercializing new knowledge. On the contrary, though developing nations are familiarizing their entrepreneurships through university spin-offs and increased intensification of industry-university relation to commoditize ready-made knowledge, but the situation is far behind to compete with the developed world. This applies both to the standardization of universityindustry relationship and to the competency of the university, which need further investigation (Kroll $\&$ Liefner 2008). In this aspect, Savitskaya (2009) argues that the contribution to the understanding of open innovation practices in developing countries resides in demonstrated role of the government for creating favorable conditions for entrepreneurs to open up and integrate into innovation system in the country. She assumed that open innovation system needs a certain level of governmental support to emerge in developing economies.

Furthermore, when comes to the question of introducing open innovation in entrepreneurships, the focus directly or indirectly goes to developed countries, even so towards large and corporate business houses. But a prospective observation this study has made is that, with increased relationship between public funded research houses and entrepreneurs, including government initiatives, the sector of business entities that belongs to the SMEs are catching up in the run by adopting open innovation, mainly in developed countries, and very recently in a few developing countries. To set the benchmarking of a post doctoral research on assessing current scenario of open innovation dynamics in developing countries this study incorporates some specific observations along this context and this chapter is the result of a horizontal study on a few countries of that category who are trying in adopting open innovation (rather, trying to be innovative) in their businesses.

Apart from the entrepreneurship development, due to the very basic inheritance of the marginal societies in developing nations, a considerable interest of the entrepreneurs among SMEs has fo- 
cused on their roles in the alleviation of widespread poverty. However, looking beyond the immediate, pressing concern of the poor, Andrew Warner (2001) has advanced the concept that SMEs are the building blocks of innovation and sustainable growth in developing countries, such as SMEs represent foci of technological creativity. Supporting Kowalski (2009) this study accepts that, these concepts are linked as sustained economic growth, which can alleviate real poverty. Hence, as SME development drives economic growth in a country, there is a concomitant reduction in poverty. Now the question appears as what could be an acceptable approach in establishing a sustained business environment in developing countries' perspective in the longer run? And, what could be the appropriate strategies they should adopt to enter into the open innovation paradigm? Moreover, as long as the developing countries are trying to adopt novel ideas and strategies as a booster of economic activity, especially by adopting open innovation strategies for the development of small and medium enterprises, the study has find that these concepts are relatively unfamiliar in developing countries.

Though Lee et al. (2010) mentioned, there is considerable literature about innovation, and various models have been suggested to describe its nature, such as product innovation and process innovation; radical innovation and incremental innovation; systemic innovation and component innovation; technology-push and market-pull; and more recently closed innovation, open innovation or crowdsourcing innovation. Models can also be divided according to their innovation processes (linear models, chain-linked models, etc.), or according to the fitness for developed or developing countries, etc. but, this research argues that models as such on developing countries perspectives are scant.

Following these observations, this study explores the role and impact of SMEs in the developing and transitional economies, and discusses about a few countries' context focusing the emancipation of SMEs policies and practices accommodating open innovation (rather, innovation). The study observes that to roll out open innovation at the grass roots level of developing and transitional countries, it needs more additional input in addition to just being innovative. Next section looks into some details about innovation in business sector in developing countries.

\section{INNOVATION AND DEVELOPING COUNTRIES}

Based on the arguments organized above, there arise several other issues in terms of implementing open innovation for SMEs development in developing and transitional countries (though the following notes emphasizes on available definitions of developing countries). Firstly, it must be understood that the term "developing countries" comprises a wide variety of nations that are at very different stages of economic development, have very heterogeneous levels of technological capabilities, and have very diversified cultural differences. Hence, the innovation appropriability dynamics will be very different, for example, in advanced developing countries such as some Latin American or Asian economies where industrial, export and innovation capabilities are more or less strong, vis à vis most least developed countries (LDCs), mainly rely on traditional agricultural activities and have poorer productive and technological capabilities. Predominantly, there is a reasonable innovation gap in between them.

Secondly, it is often thought that developing countries are mainly imitators or adopters of technologies and knowledge developed elsewhere. Hence, the debate on introducing OI strategies in developing countries is often focused on whether environments are more favorable for technological changes in those countries. While lax or strong intellectual property rights (IPRs) are thought to favor imitation, copy and reverse engineering; and hence are seen by some authors as a favorable 
factor for the deployment of learning processes that could lead in the medium and long run to the creation of genuine innovation capabilities in those countries; it is often stated that strong IPRs are a condition for developing countries to receive updated technology transfers by means of licenses and foreign direct investment (Pollitt, 2007; López, 2009).

Thirdly, reasonable policy update is desired at national and local contexts in transforming business environments in favor of open innovation. Developing countries are yet to be familiarized with the newly evolved OI strategies. Transitional countries (that are in between developed and developing situation and being in transit to be developed) are by far in a better situation to adopt new innovation. However, to enhance OI adoption and to create a sustained platform of OI, developing countries (even, transitional countries) should come up with policies at their national levels, emphasizing local businesses.

Fourthly, one has to recognize that, SMEs are critical to the economies of all countries, especially the developing ones (Payne, 2003), and encouraging innovation in SMEs remains at the heart of policy initiatives for stimulating economic development at the local, state, national and regional levels (Jones \& Tilley, 2003; Edwards, Delbridge \& Munday, 2005). According to Ernst, Mytelka and Ganiatsos (1994), innovation in developing countries is based on the continuous and incremental upgrading of existing technologies or on a new combination of them.

Realizing these issues, in recent years, there is a considerable interest among entrepreneurs in establishing SMEs in developing countries. There are probably two main reasons for this. One is the belief that SME development may prove to be an effective antipoverty initiation. The second is the belief that SME development is one of the building blocks of innovation and sustainable growth. These two reasons are of course interlinked because most of the research evidence says that growth and real poverty reduction go hand in hand. If SMEs development helps growth, more than likely it helps reduce poverty as well (Warner, 2001).

Finally, organizational approaches (with patronage from the highest corners of the government) in the form of providing assistance in finding funds, knowledge and technologies are meant to be common practices at the beginning of the innovation cycle, till it matures to take over on its own both at the local and national level. In this aspect, transitional countries can take this opportunity for being at a little advantageous position to take lead in establishing not only local and national level networks, but also regional and global networks of innovation channels.

Evidently, across Southeast and South Asia, the contribution of SMEs to the overall economic growth and the GDP is relatively high. Some examples include:

- $\quad$ Bangladesh where SMEs contribute 50\% of industrial GDP and provide employment to $82 \%$ of the total industrial sector employment;

- India, where SMEs' contribution to GDP is $30 \%$;

- Nepal, where SMEs constitute more than $98 \%$ of all establishments and contribute $63 \%$ of the value-added segment;

- Thailand, where SMEs account for more than $90 \%$ of the total number of establishments, $65 \%$ of employment and $47 \%$ of manufacturing value-added; and

- The Philippines, where SMEs comprise $99 \%$ of the total manufacturing establishments and contribute $45 \%$ of employment and $18 \%$ of value added in the manufacturing sector (Kowalski, 2009).

However, when comes the question of finding good cases or case studies or national initiatives on adoption of open innovation for SMEs development at the context of developing countries, they are rare. Although, the phenomenon on innovation 
of SMEs has captured the interest of many scholars, few studies have been found on studying the issue from the developing countries' perspective.

Literature on innovation indicates that over the last two decades, there has been a systematic and fundamental change in the way firms undertake innovating activities. Particularly, there has been a tremendous growth in the use of external networks by firms of all sizes. Innovation is seen as a process which results from various interactions among different actors. Inter-organizational and cross-sectoral networks, which facilitate the accelerated flows of information, resources and trust necessary to secure and diffuse innovation, have emerged as leaders. However, as SMEs with scarce resources, have less $\mathrm{R} \& \mathrm{D}$, and generally face more uncertainties and barriers to innovation, networks represent a complementary response to insecurity arising from development and use of new technologies, while reducing uncertainties in innovation. Moreover, in the era of "open innovation", according to Chesbrough (2003), firms consistently rely on external sources of innovation by emphasizing the ideas, resources and individuals flowing in and out of organizations, searching for and using a wider range of external ideas, knowledge and resources, networks, which are becoming essential for the creation of successful innovations for SMEs (Li, Chen \& Zheng, 2010; Zeng, Xie \& Tam, 2010; Chesbrough, 2011), but seems unfamiliar in developing countries.

Furthermore, in the perspective of innovation systems in developing countries, production and exchange of knowledge (mainly technical; internal or external or both) and information are not the only prerequisites for innovation; several additional factors play as key roles, such as policy, legislation, infrastructure, funding, and market developments (Klein-Woolthuis, Lankhuizen \& Gilsing, 2005). In addition to these, the concept of knowledge absorption is often used related to intra- and inter- firm knowledge transfer and ability to implement the acquired knowledge, and the notion of absorptive capacity can be related to cross- region or cross-country knowledge exchange. This is most relevant to developing countries, who are believed to be imitators, rather than innovators, and their innovative development happens in terms of adaptation of existing technologies to satisfy local realities (Feinson, 2003; Savitskaya, 2009).

This chapter likes to discuss a few SMEs development initiatives in five developing countries in terms of adopting innovative approaches. The study has tried to collect researches or examples based on policies and practices adopting open innovation. The selection criterion follows random sampling and availability of searched literature within accessible search engines.

\section{CASE DESCRIPTIONS}

Small and medium enterprises are being recognized in different ways in different countries .Most countries have adopted the benchmarks of employment. Some classify them in terms of assets, a few in terms of sales and others, in terms of fund. In a few countries, a hybrid definition is used, such as employment and assets or turnover. Although definition differ across countries, they have one thing in common; the vast majority of SMEs are relatively small and over $95 \%$ of SMEs in Asia employ less than 100 people. Based on this, broad comparison on the characteristics and role of SMEs is still possible even with differing definitions (Pandey \& Shivesh, 2007).

This study has considered five countries from Africa and Asia. Among them the two countries in Africa, South African one is based on the Sekhukhune Living Labs experience and Ugandan one is showing the national contexts focusing SMEs development. Among the three Asian countries; from Bangladesh, India and China, the national policy perspectives have been illustrated, which show evolution of entrepreneurships towards innovation paradigm. Countries in this section have been selected at random basis, however, the intention is to find out the trend of doing any 
innovative (rather open innovative) entrepreneurships among these countries, any initiative taken by their governments to promote innovative entrepreneurships, and to find out any catalytic agents in this aspect. They are being described next following alphabetical order.

\section{Bangladesh}

Government of Bangladesh formulated the National Industrial Policy 2005 by giving emphasize for developing Small and Medium Enterprises ${ }^{1}$ as a thrust sector to achieve a balanced and sustainable industrial development in the country with the vision for facing the challenges of free market economy and globalization. In the policy strategies, smooth and sustainable development of SMEs all over the country has been considered as one of the important vehicles for accelerating national economic growth including poverty alleviation, and generation of employment. Most of the industrial enterprises in Bangladesh are typically SME in nature. Generally SMEs are found to be labor intensive with relatively low capital intensity. SMEs also possess a character of privilege as cost effective and comparative cost advantages by nature. In this aspect, the SME policy strategies have been formulated in line with the acknowledged principles for achieving the Millennium Development Goals (MDGs) by the Government (Govt. of Bangladesh, 2005a).

Furthermore, the provisions of facilities for attracting foreign investments (foreign direct investments) have been envisaged in the Industrial Policy. The government has taken an initiative to formulate a separate SME policy to provide entrepreneurs with necessary guidance and strategic support in respect of the establishment of SME industries all over the country (Govt. of Bangladesh, 2005b).

A few of the broad objectives of the SME policy strategies are to:
- $\quad$ accept SMEs as an indispensable player in growth acceleration and poverty reduction, worthy of its total commitment in the requisite overall policy formulation and implementation;

- $\quad$ SME policy strategies shall essentially be linked with broad based and integrated manner in line with the poverty reduction strategy paper of the Government of Bangladesh;

- $\quad$ encourage and induce private sector development and promote the growth of foreign direct investment (FDI), develop an acceptable code of ethics and establish good governance, ICT based knowledge management and customer supremacy in the market alliances;

- $\quad$ identify and establish the network of infrastructure and institutional delivery mechanisms that facilitate the promotion of SMEs at the national level;

- $\quad$ re-orient the existing fiscal and regulatory framework and government sponsored institutions supporting the goals of SME policy;

- have credible management teams in terms of the delivery of needed services, leadership, initiation, counseling, mentoring and tutoring;

- create innovative but rewarding arrangements so that deserving and especially enterprises with desired entrepreneurial qualifications and promise can be offered financial incentives within industries prescribed on some well-agreed bases;

- $\quad$ assist implement dispute settlement procedures that proactively shield small enterprises especially from high legal costs and insidious harassments; and

- $\quad$ take measures to create avenues of mobilizing debt without collaterals to match (either using debt-guarantee schemes or mapping intellectual-property capital into pseudo-venture capital) in order to assist 
small enterprises in dealing with their pervasive lack of access to finance (Govt. of Bangladesh, 2005a). This study notes that use of debt-guarantee scheme, mapping of intellectual property or concept of venture capital are very basic ingredients of open innovation strategies.

For promotional support the following booster sectors has been identified and the list has been set to be reviewed every three years:

- Electronics and Electrical Engineering,

- $\quad$ Software Development, and

- $\quad$ Light Engineering, comprising

- Agro-processing and related business;

- Leather and Leather goods;

- Knitwear and Ready Made Garments;

- $\quad$ Plastics and other synthetics;

- Healthcare and Diagnostics;

- Educational Services;

- Pharmaceuticals/ Cosmetics/

Toiletries; and

- Fashion-rich personal effects, wear and consumption goods (Govt. of Bangladesh, 2005a).

Moreover, the government has established an SME Foundation as a pivotal platform for the delivery of all planning, developmental, financing, awareness-raising, evaluation and advocacy services in the name of SME development as one of the crucially-important element of poverty alleviation. The Foundation suppose to provide a one-window delivery of all administrative facilities, including some resources needed for capacitybuilding in appropriate industry association(s), for SMEs in Bangladesh (Govt. of Bangladesh, 2005a; 2005b).

\section{China}

China is attempting to catch-up in terms of innovating their entrepreneurships, which is fundamentally different from earlier latecomers like Japan and South Korea. The basic elements of Chinese catching up strategy are: market size, market-oriented innovation, global alliance and open innovation, spillover of FDI and role of government. Moreover, the core capability of Chinese company is an integration capability of market knowledge, outsourcing and learning (Liu, 2008).

Since the realization of the open policy in 1978, China has made great efforts to change from a highly centralized planned state to the near market economy. The role of SMEs has been expanding in the changing socio-political context. They not only play a greater role in the economies (accounting for more than $99 \%$ of all firms being SMEs), but also contribute in a large extent to the increased levels of business activity and employment (Siu, 2005). Zeng, Xie \& Tam (2010) argue that, the manufacturing industry is the main driving force of social development and economic growth in developing countries. In this context, Zeng, Xie \& Tam (2010) mention that China, with more than two decades of market oriented reform, there has been a rapid growth in the manufacturing industry. Hence, it is necessary to explore the external cooperation network of manufacturing SMEs in order to help them improve their industrial competitiveness. However, there is a paucity of studies on the impact of external cooperation network on the innovation of Chinese manufacturing SMEs. This study notes that collaborative networking is one of the most effective preconditions for adopting OI strategies.

Using a structured questionnaire survey, Zeng, Xie \& Tam (2010) examine the innovation networking activities of some surveyed SMEs in Shanghai, the largest city and economic center in China. Their study aims to explore the relationships between different cooperation networks and innovation performance of SME. Based on a survey of 137 Chinese manufacturing SMEs, they empirically explore the relationships between different cooperation networks and innovation performance of SME using the technique of 
structural equation modeling (SEM). Their study finds that there are significant positive relationships between inter firm cooperation, cooperation with intermediary institutions, cooperation with research organizations and innovation performance of SMEs, of which inter firm cooperation has the most significant positive impact on the innovation performance of SMEs.

This study supports the above mentioned parameters as the basic building block in establishing a platform of open innovation. However, the result of Zeng, Xie \& Tam (2010) reveals that the linkage and cooperation with government agencies do not demonstrate any significant impact on the innovation performance of SMEs. Moreover, their findings confirm that the vertical and horizontal cooperation with customers, suppliers and other firms plays a more distinct role in the innovation process of SMEs than horizontal cooperation with research institutions, universities or colleges, and government agencies, which is quite opposite to the context of developed countries. This study suggests that further studies need to be carried out to re-confirm this hypothesis or find out any future diversions.

\section{India}

In India, the term small scale industries ( $\left.\mathrm{SSIs}^{2}\right)$, is used far more often than SMEs and is based upon investment in assets ${ }^{3}$ (Saini \& Budhwar, 2008). However, despite various liberalizations and schematic changes to meet the emerging requirements of the business sector, availability of finance continues to be a major problem for small enterprises in India. Realizing this fact, some of the development financial institutions (DFIs) and forward looking commercial banks have put in operation a number of innovative schemes, and among them the Small Industries Development Bank of India (SIDBI) has taken the lead. It has been observed that the majority of the experiments have started showing good results. Furthermore, the SSI sector plays a significant role in the
Indian economy. For the past one decade, it has been consistently registering about three per cent higher real growth rate in terms of GDP (8.9 per cent during 1999-2000) compared to the growth recorded by the industrial sector as a whole. The SSI sector contributes over 41 per cent of the total industrial production, 31 per cent of the country's total exports, and jointly with traditional industries (for example Khadi, handloom, handicrafts, sericulture, and coir) the relative percentage goes up to 58 per cent (Narain, 2001).

In terms of finance, transaction lending such as asset based lending, factoring and leasing have been in use to fund SMEs for some time, and there is some evidence of relationship lending in India. Moreover, in developing countries, the private economy would comprise largely of family businesses. It is estimated that in India, family businesses account for $70 \%$ of the total sales and net profits of the biggest 250 private-sector companies (Economist, 1996), and almost all the micro-small-and-medium-enterprise (MSME) would be family firms. Inter-family relationships and family succession play an important role in the performance of family firms, and financial institutes would need to take this into account in their credit decisions. A study by Marisetty, Ramachandran \& Jha (2008) finds that family businesses in India where succession takes place without fights and splits show higher profitability (Thampy, 2010). This study notes that India is accepting several strategies towards open innovation, such as providing financial supports; liberalizing market conditions; adopting lending, factoring and leasing; and foremost promoting networking.

\section{South Africa}

In European context, supporting open innovation among SMEs, Living Labs are providing significant input in terms of co-creation, exploration, experimentation and evaluation ${ }^{4}$. As a knowledge centre of the European Network of Living Labs 
(ENoLL), the Sekhukhune Living Lab focuses on small, medium and micro-enterprises (SMMEs) which are regarded as important growth engines in South Africa. However, several barriers are inhibiting rural entrepreneurship and access to mainstream or global supply chains and markets. Schaffers et al. (2007), in their research mentions that, long distances, high transport/transaction costs and low economies of scale are the consequences of typical rural conditions such as physical remoteness and low economic activity levels. Furthermore, the problems associated with these barriers worsen dramatically where roads are poor, telecommunications bandwidth is limited or expensive, and many rural entrepreneurs have limited computer literacy and do not own a truck, motorcar or computer. These are the typical complexities faced by rural entrepreneurs in most of the developing countries, and in South Africa's "deep rural areas" such as Sekhukhune.

Through ENoLL, Sekhukhune Living Lab introduces a range of services through the facilitation of so called Infopreneurs, which are micro, self-sustainable service enterprises that channel and deliver services for local SMMEs and citizens into the community. These Infopreneurs are the 1st tier target SMME group of the work and interventions of the C@R Living Lab. They provide knowledge-based services such as crossorganizational business process enabling, SWOT analysis and logistics brokerage to assist start-up, grow and cluster other SMME's in various sectors (for example, health, mining, or construction).

These Infopreneurs are being deployed in existing infrastructure and getting benefit from ongoing local initiatives supported by the SouthAfrican government. Franchise-like agreements are shaping the collaboration among partners. However, the focus of Living Lab development is on establishing collaboration tools and processes, particularly addressing the accessibility of knowledge-based services that are relevant to local SMME businesses, in harnessing increased mobile connectivity and enabling rural service channels that enhance effective collaboration amongst SMMEs in communities and between first and second economy enterprises.

The ubiquitous infrastructure shortcomings of South-Africa (such as, constricted bandwidth or poor infrastructure) are being taken into account when setting up these knowledge service agents. By forming clustered enterprises via Infopreneur services, consolidation of supply chain volumes is achieved with lower transaction and transportation costs. The strategy is to create Infopreneur service bundles to enhance local business and geo-economic intelligence that helps SMMEs to seamlessly interoperate among each other and first economy enterprises (Schaffers et al., 2007). Intermediaries are an essential element of promoting open innovation dynamics in diverse and difficult environments, as such this study notes.

\section{Uganda}

In Uganda, $\mathrm{SMEs}^{5}$ are increasingly taking the role of the primary vehicles for the creation of employment and income generation through self-employment, and treated as tools for poverty alleviation. SMEs also provide the economy with a continuous supply of ideas, skills and innovation necessary to promote competition and at the same time, efficient allocation of scarce resources.

Furthermore, mentioned by Kasekende (2001), a few strong SMEs in Uganda, like Capital Radio, Kabira International School, Masaba Cotton Co. Ltd and Africa Basic Foods were formed through joint venture arrangements with foreign partners from the United Kingdom and the United States. These and other SMEs have provided domestic linkages, comprising link between agriculture and industry and between SMEs and large-scale industries. This has created opportunities for employment and income generation both in rural and urban areas at relatively low cost, thus ensuring a more equitable income distribution. In turn, the stimulation of activities in both rural and urban areas has mitigated some of the problems that un- 
Table 1. Observed Tendencies on SMEs development

\begin{tabular}{|l|l|l|}
\hline \multicolumn{1}{|c|}{ Country } & \multicolumn{1}{|c|}{ Pattern at national context } & \multicolumn{1}{c|}{ Observed tendency } \\
\hline Bangladesh & Policy initiation & $\begin{array}{l}\text { Awareness development, acceptance of policy, initiation of policy, } \\
\text { and patronization from the government }\end{array}$ \\
\hline China & $\begin{array}{l}\text { Action through vertical and horizontal } \\
\text { integration }\end{array}$ & $\begin{array}{l}\text { Cooperation among customers, suppliers, other firms, research } \\
\text { institutions, universities and government agencies; Market driven } \\
\text { initiation accommodating global competition, dependency on } \\
\text { FDI, and patronization from the government }\end{array}$ \\
\hline India & Identification & Identify the potential business sector where thrust should be given \\
\hline South Africa & Clusterization and Institutionalization & $\begin{array}{l}\text { Build a sustainable infrastructure serving local community at } \\
\text { local context }\end{array}$ \\
\hline Uganda & Utilization & $\begin{array}{l}\text { Application of appropriate strategies at designated levels of } \\
\text { enterprises }\end{array}$ \\
\hline
\end{tabular}

planned urbanization tends to create, thus offering an efficient and progressive decentralization of the economy. In this aspect, SMEs play a crucial role in creating opportunities to achieve equitable and sustainable growth. SMEs in Uganda are providing employment and income generation opportunities to low income sectors of the economy.

However, due to their characteristics and nature, SMEs in Uganda suffer from constraints that lower their resilience to risk and prevent them from growing and attaining economies of scale. The challenges are not only in the areas of financial investment and working capital, but also in human resource development, market access, and access to modern ICTs. Furthermore, access to financial resources is constrained by both internal and external factors. Internally, most SMEs lack creditworthiness and management capacity, so they have trouble securing funds for their business activities, for example procuring raw materials and products, and investing in plant and equipment. From the external viewpoint, SMEs are regarded as insecure and costly businesses to deal with because they lack required collateral and have the capacity to absorb only small amount of funds from financial institutions. Foremost, due to high intermediate costs, including the cost of monitoring, they are rationed in their access to credits and having difficulties in enforcing loan contracts (Kasenkende, 2001).
To overcome such constraints, the government and other players such as the Bank of Uganda (BOU) have designed programmes and policies to support SMEs that are market driven and nonmarket distorting. The government has created stable macroeconomic conditions, liberalized the economy, and encouraged the growth of the microfinancing business. In conjunction with donors, the government has designed a medium-term competitive strategy and a Rural Financial Services Programme to benefit SMEs. However, the challenge to SMEs in accessing financial services will remain dependent on how they themselves increase their creditworthiness (Kasekende, 2001). This study observes that to widen OI strategies at the national and local level, Uganda has been moving in the appropriate direction.

\section{SYNTHESIS AND THE FRAMEWORK}

Synthesizing the countries of this study provides different dimensions of business growth in their countries, accommodating innovation. Ranging from policy initiation to networking, to liberization, to institutionalization are evident there. Table 1 shows various aspects of the synthesis in the form of a framework, however, this does not mean that any country is superseding another. 


\section{CURRENT CHALLENGES}

This section starts using a quote of Saini and Budhwar about the understanding on SMEs, saying "The concept of SME itself is quite problematic" (2008, p. 417). This study finds another important quote from their paper, where Storey notes, "there is no single, uniformly acceptable, definition of a small firm". There are differences as to size, shape and capital employed. In the USA there is no standard definition of small business. Even a firm employing up to 1500 employees is considered as small by American Small Business Administration. The concept in USA is industryspecific; mostly income and persons employed will determine whether a firm falls in the category of small business or not" (1994, p. 8).

The European Commission classifies firms according to the number of employees as: micro (0-9), small (10-99) and medium (100-499). However, in Oslo Manual (OECD, 2005) the EC has incorporated turn over, in addition to the number of employees. In China, it includes companies employing less than 200 persons; and in Japan those employing less than 300 persons are considered to be SMEs (Srivastava, 2005: 166). Even, sometimes the definition of SMEs depends on the stage of national economic development and the broad policy purposes for which the definition is required (observed in case of Bangladesh, or India, or USA). But, the essential fact is that, whatever may be the definitional problems, SMEs occupy an important place in the economy of most countries; especially they are favored in developing countries due to their employment potential (Saini \& Budhwar, 2008).

Furthermore, access to finance has been identified as a key element for SMEs to succeed in their drive to build productive capacity, compete, create job opportunities and contribute to poverty alleviation in developing countries. Without finance, neither SMEs cannot acquire or absorb new technologies, nor they can expand to compete in global markets or even establish business linkages with larger firms. Finance has been identified in many business surveys as the most important factor determining the survival and growth of SMEs in both developing and developed countries (including transitional countries). Access to finance allows SMEs to undertake productive investments to expand their businesses and acquire the latest technologies, thus ensuring their competitiveness. Poorly functioning financial systems can seriously undermine the microeconomic environment of a country, resulting in lower growth in income and employment (UNCTAD Secretariat, 2001)

Despite their dominant numbers and importance in job creation, SMEs face difficulty in obtaining formal credit or equity. For example, maturities of commercial bank loans made available to SMEs are often limited to a period far too short to pay off any sizeable investment. Meanwhile, access to competitive interest rates is reserved for only a few selected blue-chip companies while loan interest rates offered to SMEs always remain high. Moreover, banks in many developing countries traditionally lent overwhelmingly to the government, which are less risky and offer higher returns. Such practices have congested most private sector borrowers and increased the cost of capital for them. Governments cannot expect to have a dynamic private sector as long as they absorb the bulk of private savings. In the case of venture capital funds (an essential ingredient of open innovation entrepreneurship), governments have been concentrated in high technology sectors. Similarly, the international financial institutions have ignored the plight of SMEs. These preferences and tendencies have aggravated the lack of financing for SMEs (UNCTAD Secretariat, 2001).

Technological advancements have contributed to remarkable changes to the nature of current production systems. This has also created impact on the nature of work, workers and skills involved. SMEs may take benefit from these advancements in their operations, but they do not recognize the critical role of effective human resource policies for their success. Furthermore, the need for a 
skilled workforce in SMEs certainly becomes apparent during periods of such technological changes. Particularly, SMEs have to undergo some changes when they compete with global companies and other large buyers, as they are dependent on supply contracts from the same. This puts substantial pressure on SMEs to control both their costs and quality and meet the different legal requirements. Moreover, this poises a serious challenge for SMEs, especially for those operating in developing countries with labor-intensive technologies, where labor cost is a major concern. Many of them resort to disputed practices, such as employment of child labor to reduced labor costs and violation of labor standards including denial of minimum wage, and other minimum-work conditions. Majority of them also lack access to relevant data and information about new markets, legal provisions regulating their working, and product innovations, which hinders their survival. In addition to these, it has been found that their accessibility to professional management tools is almost absent (Zeng, Xie \& Tam, 2010).

In terms of innovation, not all countries have the opportunity or ability to capitalize on the opportunity to catch up. Specially, for a developing country, it is not easy to proceed from stage of imitation to stage of innovation (Zeng, Xie \& Tam, 2010). Bell and Pavitt (1993) pointed out, just installing large plants with foreign technology and foreign assistance will not assist in the building of technological capability. The prevailing fact is that the relation between competition patterns, productive structures and innovation in developing countries are very different from that in developed countries, and hence one should also expect to find differences in the pattern of use of intellectual property rights (IPRs) and other innovation mechanisms. Furthermore, there are differences when comparing developing countries at different stages of industrial and technological development (López, 2009). Hence, researching into open innovation focusing SMEs development in developing countries requires further intensive study and research.

This section concludes with a final sentence that, among these five nations, being driven by geographical, cultural, economical and most of all economical aspects, are very different from each other in achieving innovation in their entrepreneurships, which is a challenge to develop a generic framework for developing countries. However, as this research continues, efforts will be given to include a few more countries of similar socioeconomic-cultural contexts and in-depth study will be carried out.

\section{RECOMMENDATIONS AND FUTURE RESEARCH}

From this study on a few country specific aspects of SMEs development, if one likes to interpret them towards the dimension of open innovation, the question will arrive, as how important open innovation thinking should be at the national level to guide the policy makers and other decision support systems in policymaking. In terms of adopting open innovation, especially in developing countries, there may be other priorities in policymaking due to the relatively modest absorptive capacity of incumbent enterprises and under-developed innovation institutions. In such countries it would probably easier to start with the relatively simple guidelines with simpler framework, for example developing basic innovation and interaction skills, rather than starting with more sophisticated interventions to enhance technology markets or stimulate corporate entrepreneurship (matured stages of technology exploration or technology exploitation). Future work may explore if there is an optimal sequence in the innovation system as how to adopt various open innovation policy guidelines, and if the developed framework needs to be refined for this purpose (De Jong, Vanhaverbeke, Kalvet \& Chesbrough, 2008; Rahman \& Ramos, 2010; Gassmann, Enkel \& Chesbrough, 2010). 
In recent years banks in developed countries have launched a number of initiatives that both improve the profitability of lending to SMEs, and provides SMEs with better access to finance and financial products that are better tailored to their needs. A number of leading banks have demonstrated that providing financial services to SMEs can be turned into a profitable business. Although the business environments in developing countries and developed countries differ in many respects, the problems of servicing SME customers remain similar, such as high perceived risk, problems with information asymmetry and high administrative costs. Hence, recent innovations in developed countries to improve SMEs access to credit may provide valuable insights for developing country banks to become more SME-oriented and increase the volume and the quality of their services (Warner, 2001).

Davidsson (2006) forwarded the idea of the Small Business Innovation Program, and suggested that, perhaps in one way to adjust the conditions and challenges of a developing country one can pursue the following focus areas:

- $\quad$ Education, training and skill development programmes for entrepreneurship;

- $\quad$ Routines, inductions and contacts for initiating start-ups;

- Communication with government officials to better understand legislation and regulation in the area of entrepreneurships, including marketing environments;

- Availability of skills those are useful for potential consumer markets;

- Improving online access by skills and resources;

- Access to financial resource and contacts for foreign direct investments;

- $\quad$ Strengthen the technological capacity;

- Successful e-business models; and

- Establish stronger, more effective representation of small enterprises' interests at local, and national government and international level.

Foremost, there is an urgent need to make the best out of the public and private resources invested in fundamental and applied research. Both budget pressures and the need to solve crucial challenges, such as transitioning to an environmentally sustainable economy and supporting the equitable growth of developing countries mean that science will be required to generate technology at an ever-increased rate to maintain the continuous stream of social and market driven innovations (Ruiz, 2010).

\section{CONCLUSION}

SMEs are in general initiated by a single entrepreneur or a small group of people, and are often managed by owner-managers. Their organizational structures are typically flat. SMEs do not have many layers (mainly due to small number of both employees/supervisors and specializations in human skills) because the owner/s is/are mostly at the top of decision making affairs (which still keeps them bureaucratic as most of the times employees do not dare to challenge the supervisors/owner/s). However, the good thing come from this nature is that it adds to their flexibility. Many researchers argue that entrepreneurs mostly seek to derive several advantages by undertaking operations at a smaller level in terms of flexibility, informality, sustainability, and structural adaptability (Zeng, Xie \& Tam, 2010).

However, this study argues that, to observe the rolling out of innovation processes in developing countries, a multi-facet research has to be carried out, including broader aspects of the entire context of open innovation dynamics and incorporating larger sample size. Adoption of a generic definition of SMEs in terms of operating and sustained context, learning about conceptual and behavioral challenges, formulation of a broad 
based framework, and above all perception on human skills on innovation are among many factors to explore. The discussions presented so far, is an attempt to overview the open innovation paradigm and relevant public policy context in a developing country. The indicative remarks may offer insights for future research in the fields of open innovation and innovation policy initiation. This study had its limitations. Scant literature and lack of necessary tools, such as survey or interview or other instruments are among them. Nevertheless, introducing these tools is expected to bring along opportunities for further research.

\section{REFERENCES}

Bell, M., \& Pavitt, K. L. R. (1993). Technological accumulation and industrial growth: contrasts between developed and developing countries. Industrial and Corporate Change, 2, 157-210. doi:10.1093/icc/2.1.157

Carayannis, E. G., Popescu, D., Sipp, C., \& Steward, M. (2006). Technological learning for entrepreneurial development (TL4ED) in the knowledge economy (KE): Case studies and lessons learned. Technovation, 26, 419-443. doi:10.1016/j.technovation.2005.04.003

Chesbrough, H. W. (2003). Open innovation: The new imperative for creating and profiting from technology. Boston: Harvard Business School Press.

Chesbrough, H. W. (2011). Bridging Open Innovation to Services, MIT. Sloan Management Review, 52(2), 85-90.

Davidsson, J. (2006). Small Business Innovation Program: Business development and entrepreneurial training with intellectual property in developing countries. B-Open Nordic AB.
De Jong, J. P. J., Vanhaverbeke, W., Kalvet, T., \& Chesbrough, H. (2008), Policies for Open Innovation: Theory, Framework and Cases, Research project funded by VISION Era-Net, Helsinki: Finland

Economist (October 05, 1996). The family connection. 341(7986): 62

Edwards, T., Delbridge, R., \& Munday, M. (2005). Understanding innovation in small and medium-sized enterprises: a process manifest. Technovation, 25(10), 1119-1127. doi:10.1016/j. technovation.2004.04.005

Ernst, D., Mytelka, L., \& Ganiatsos, T. (1994). Technological Capabilities: A Conceptual Framework, Mimeo. Geneva: UNCTAD.

Feinson, S. (2003). National innovation systems overview and country cases. In Sarewitz, D. (Ed.), Knowledge Flows, Innovation, and Learning in Developing Countries. New York: Rockefeller Foundation.

Gassmann, O., Enkel, E., \& Chesbrough, H. (2010). The future of open innovation. $R \&$ D Management, 40(3), 213-221. doi:10.1111/ j.1467-9310.2010.00605.x

Govt. of Bangladesh (2005a). Policy Strategies for Small \& Medium Enterprises (SME) Development in Bangladesh, Government of the People's Republic of Bangladesh

Govt. of Bangladesh (2005b). Bangladesh Industrial Policy 2005, Ministry of Industries, Government of the People's Republic of Bangladesh

Jones, O., \& Tilley, F. (Eds.). (2003). Competitive Advantage in SMEs: organizing for innovation and change. Chichester: Wiley.

Kasekende, L. (2001). Financing SMEs: Uganda's Experience. In Improving the Competitiveness of SMEs in Developing Countries: The Role of Finance to Enhance Enterprise Development (pp. 97-107). New York, Geneva: United Nations. 
Klein-Woolthuis, R., Lankhuizen, M., \& Gilsing, V. (2005). A system failure framework for innovation policy design. Technovation, 25, 609-619. doi:10.1016/j.technovation.2003.11.002

Kowalski, S. P. (2009). SMES, Open Innovation and IP Management:Advancing Global Development, A presentation paper on the Theme 2: The Challenge of Open Innovation for MSMEs - SMEs, Open Innovation and IP Management-Advancing Global Development, WIPO-Italy International Convention on Intellectual Property and Competitiveness of Micro, Small and Medium-Sized Enterprises (MSMEs), December 10-11, 2009, Rome, Italy

Kroll, H., \& Liefner, I. (2008). Spin-offenterprises as a mean of technology commercialisation in a transforming economy - evidence from three universities in China. Technovation, 28, 298-313. doi:10.1016/j.technovation.2007.05.002

Lee, S., Park, G., Yoonc, B., \& Park, J. (2010). Open innovation in SMEs-An intermediated network model. Research Policy, 39, 290-300. doi:10.1016/j.respol.2009.12.009

Li, F., Chen, J., \& Zheng, G. (2010). OpenDisruptive Innovation: An avenue for developing countries' independent innovation, A paper from 2010 IEEE International Conference on Management of Innovation and Technology (ICMIT), (pp.737-742), 2-5 June 2010, Singapore.

Liu, X. (2008).China's Development Model: An Alternative Strategy for Technological Catch-Up, SLPTMD Working Paper Series No. 020, University of Oxford, UK.

López, A. (2009). Innovation and Appropriability, Empirical Evidence and Research Agenda. In: The Economics of Intellectual Property: Suggestions for Further Research in Developing Countries and Countries with Economies in Transition, World Intellectual Property organization, (pp. 1-40)
Marisetty, V., Ramachandran, K., \& Jha, R. (2008). Wealth effects of family succession: A case of Indian family business groups. Working Paper. Indian School of Business

Narain, S. (2001). Development Financial Institutions' and Commercial banks' Innovation Schemes for Assisting SMEs in India. In Improving the Competitiveness of SMEs in Developing Countries: The Role of Finance to Enhance Enterprise Development (pp. 81-87). New York, Geneva: United Nations.

OECD. (2005). Oslo Manual: Guidelines for Collecting and Interpreting Innovation Data (3rded.). Paris: Organization for Economic Co-operation and Development.

Pandey, A.P. \& Shivesh (2007). Indian SMEs and their uniqueness in the country, Munich Personal RePEc Archive, MPRA Paper No. 6086, posted 04. December 2007, Available online at http:// mpra.ub.uni-muenchen.de/6086/

Payne, J. E. (2003) E-Commerce Readiness for SMEs in Developing Countries: a Guide for Development Professionals, 07 May- last update, viewed 28 September 2004, (online), Available at URL: http://learnlink.aed.org/Publications/ Concept_Papers/ecommerce_readiness.pdf

Pollitt, C. (2007). Time, Policy, Management Governing with the Past. Oxford University Press.

Rahman, H., \& Ramos, I. (2010). Open Innovation in SMEs: From Closed Boundaries to Networked Paradigm. Issues in Informing Science and Information Technology, 7, 471-487.

Ruiz, P.P. (2010).Technology \& Knowledge Transfer Under the Open Innovation Paradigm: a model and tool proposal to understand and enhance collaboration-based innovations integrating $C-K$ Design Theory, TRIZ and Information Technologies, Dissertation for the Master of Science in Innovation and Technology, Management School of Management, University of Bath, UK. 
Saini, D. S., \& Budhwar, P. S. (2008). Managing the human resource in Indian SMEs: The role of indigenous realities. Journal of World Business, 43, 417-434. doi:10.1016/j.jwb.2008.03.004

Savitskaya, I. (2009). Towards open innovation in regional Innovation system: case St. Petersburg, Research Report 214. Lappeenranta: Lappeenranta University of Technology.

Schaffers, H., Cordoba, M. G., Hongisto, P., Kallai, T., Merz, C., \& van Rensburg, J. (2007). Exploring business models for open innovation in rural living labs. A paper from the 13th International Conference on Concurrent Enterprising, (p. 13) Sophia-Antipolis, France, 4-6 June 2007

Secretariat, U.N.C.T.A.D. (2001). Best Practices in Financial Innovations for SMEs. In Improving the Competitiveness of SMEs in Developing Countries: The Role of Finance to Enhance Enterprise Development (pp. 3-58). New York, Geneva: United Nations.

Siu, W. S. (2005). An institutional analysis of marketing practices of small and medium-sized enterprises (SMEs) in China, Hong Kong and Taiwan. Entrepreneurship and Regional Development, 17(1),65-88.doi:10.1080/0898562052000330306

Srivastava, D. K. (2005). Human resource management in Indian mid size operations. In Datta (Ed.), Indian mid-sizemanufacturing enterprises: Opportunities and challenges in a globaleconomy. Gurgaon: Management Development Institute

Storey, D. (1994). Understanding the small business sector. London: International Thomson Business Press.

Thampy, A. (2010). Financing of SME firms in India Interview with Ranjana Kumar, Former CMD, Indian Bank; Vigilance Commissioner, Central Vigilance Commission. Available online 12 June 2010; doi:10.1016/j.iimb.2010.04.011
United Nations. (2006). Globalization of R\&D and Developing Countries, United Nations Conference on Trade and Development, UNCTAD/ITE/ IIA/2005/6, New York and Geneva: United Nations

Van Hemert, P., \& Nijkamp, P. (2010). Knowledge investments, business R\&D and innovativeness of countries: Aqualitative meta-analytic comparison. Technological Forecasting and Social Change, 77,369-384. doi:10.1016/j.techfore.2009.08.007

Warner, A. (2001). Small and Medium Sized Enterprises and Economic Creativity. A paper presented atUNCTAD's intergovernmental Expert Meeting on "Improving the Competitiveness of SMEs in Developing Countries: the Role of Finance, Including E-finance, to Enhance Enterprise Development", held in Geneva on 22-24 October 2001, UNCTAD/ITE/TEB/Misc.3, (pp. 61-77.)

World Business Council. (2007). Promoting Small and Medium Enterprises for Sustainable Development. Development Focus Area World Business Council for Sustainable Development. I Issue Brief, 2007.

Zeng, S. X., Xie, X. M., \& Tam, C. M. (2010). Relationship between cooperation networks and innovation performance of SMEs. Technovation, 30, 181-194. doi:10.1016/j.technovation.2009.08.003

\section{KEY TERMS AND DEFINITIONS}

Developed Economies: While there is no one set definition, but typically a developed economy refers to a country with a relatively high level of economic growth and security. Some of the most common criteria for evaluating a country's degree of development are its per capita income or gross domestic product (GDP), the level of industrialization, general standard of living and the amount of widespread infrastructure. Increasingly other non-economic factors are included in evaluating 
an economy or country's degree of development, such as the Human Development Index (HDI) which reflects relative degrees of advancement in education, literacy and health.

Developing Economies: Comprise low- and middle-income countries where most people have lower standard of living with access to fewer goods and services than most people in high-income countries. Developing countries are broadly split into two categories, the middle-income and the low-income groups.

Emerging Economies: Are the most economically progresses of developing countries. In terms of GNP per capita, they correspond to the medium-low and medium-high country groups but are characterized by a regulated and functioning securities exchange, or in the process of developing one, and the fact that shares traded on the stock exchanges must be available for purchase by foreign investors, even if subject to certain restrictions.

Entrepreneurs: An entrepreneur is a person who has possession of a new enterprise, venture or idea organizes, operates a business or businesses and assumes significant accountability for the inherent risks and the outcome.

Entrepreneurships: It is the process of discovering new ways of blending resources. When the market value generated by this new blending of resources is greater than the market value these resources can generate elsewhere individually or in some other combination, then the entrepreneur makes a profit.

First Economy Enterprises: These are the enterprises that are comprised of established businesses in sustained form.

Second Economy Enterprises: These are the form of enterprises that are mainly belong to the working poor, or marginalized communities, and working in the informal economy.

\section{ENDNOTES}

1 Enterprises shall be categorized using the following definition (fixed investment implies exclusion of land and building, and valuation on the basis of current replacement cost only): Small enterprise: an enterprise should be treated as small if, in today's market prices, the replacement cost of plant, machinery and other parts/components, fixtures, support utility, and associated technical services by way of capitalized costs (of turn-key consultancy services, for example), etc, excluding land and building, were to be up to Tk. 15 million; Medium enterprise: an enterprise would be treated as medium if, in today's market prices, the replacement cost of plant, machinery, and other parts/components, fixtures, supportutility, and associated technical services (such as turn-key consultancy), etc, excluding land and building, were to be up to Tk. 100 million; a. For non-manufacturing activities (such as trading or other services), the Taskforce defines: Small enterprise: an enterprise should be treated as small if it has less than 25 workers, in full-time equivalents; Medium enterprise: an enterprise would be treated as medium if it has between 25 and 100 employees.

2 In India, the industrial sector has two broad segments viz., (a) Small Scale Industries (SSI) and (b) Others (i.e. medium and large industries). The Government of India notifies the definition of small-scale industry from time to time based on the investment ceiling. The present definition is, "an industry in the small scale sector shall have investment in plant and machinery not exceeding INR 10 million" (approx. US\$22,000). A subcomponent of micro enterprises, known as the "Tiny Sector" forms part of the overall SSI sector. Medium sized industries are out of the purview. India, thus, follows the concept of SSIs and not SMEs. 
3 In India, until recently there has been no formal concept of SME or medium enterprises. However, the term small scale industry (SSI) is well known; this is different from the SME sector in other countries. The Government of India had a policy of providing assistance of different types to SSIs through various state agencies. Lately, Indian Parliament has enacted the Micro, Small and Medium Enterprises Development Act, 2006.1 As per this Act, medium manufacturing or production enterprises are those which have an investment in plant and machinery between Rs. 50 million and 100 million ( $1 \$$ US $=$ Rupees 40.10 approximately in July 2007). The investment referred to in this definition is that in "initial fixed assets" i.e., the plant and machinery (which excludes land \& building). Under this Act, a micro enterprise has been defined as one where the investment in plant and machinery does not exceed Rs. 2.5 million and a small enterprise as one where such investment is more than Rs. 2.5 million but does not exceed Rs. 50 million. Whereas, a medium enterprise is one in which the investment limit is between Rs. 50 million and Rs. 100 million. In this Act there is no reference to the term SME. One may, however, combine the definitions of small and medium enterprises to derive a concept of SME. This would mean that an SME in the Indian context is an enterprise in which the investment in plant and machinery is between
2.5 million and 100 million. 2 The definition of the terms "small" and "medium" enterprise in India is investment specific, while in the rest of the world it reflects a combination of factors including terms of employment, assets or sales or combination of these factors (Saini \& Budhwar, 2008). http://www.openlivinglabs.eu SMEs are widely defined in terms of their characteristics, which include the size of capital investment, the number of employees, the turnover, the management style, the location, and the market share. Country context plays a major role in determining the nature of these characteristics, especially, the size of investment in capital accumulation and the number of employees. For developing countries, small-scale generally means enterprises with less than 50 workers and medium-size enterprises would usually mean those that have 50-99 workers. In Uganda, a small-scale enterprise is an enterprise or a firm employing less than 5 but with a maximum of 50 employees, with the value of assets, excluding land, building and working capital of less than Ugshs. 50 million (USD 30,000 ), and an annual income turnover of between Ugshs. 10-50 million (USD 6,000-30,000). A medium-size enterprise is considered a firm, which employs between 50-100 workers. Other characteristics have not been fully developed. 